\title{
Controle operacional da fluoretação da água de Niterói, Rio de Janeiro, Brasil
}

\author{
Operational control of water fluoridation \\ in Niterói, Rio de Janeiro, Brazil
}

Lucianne Cople Maia 1

Ana Maria Gondim Valença 2

Eduardo Lúcio Soares 3

Jaime Aparecido Cury 4

\footnotetext{
1 Departamento de Odontopediatria e Ortodontia, Faculdade de Odontologia, Universidade Federal do Rio de Janeiro. Av. Brigadeiro Trompowski $s / n$, Rio de Janeiro, $R J$ 21941-590, Brasil. rorefa@microlink.com.br 2 Departamento de Clínica e Odontologia Social, Centro de Ciências da Saúde, Universidade Federal da Paraíba. Campus Universitário $s / n$, João Pessoa, $P B$ 58051-900, Brasil. 3 Centro de Ciências Médicas, Universidade Federal Fluminense. Rua Marquês do Paraná 308, Niterói, RJ 24033-900, Brasil. 4 Departamento de Ciências Fisiológicas, Faculdade de Odontologia de Piracicaba. Av. Limeira 901, Piracicaba, SP 13414-018, Brasil. jcury@fop.unicamp.br
}

\begin{abstract}
The aim of this study was to evaluate the operational control of water fluoridation at the city water supply plant in Niterói, Rio de Janeiro, Brazil, from January to December 2000. The water treatment supervisor filled out a questionnaire on the control of water fluoridation. In addition, water samples were collected every two weeks for fluoride analysis before and after treatment. Samples were analyzed by an independent laboratory using an ion-specific electrode. According to the water treatment supervisor, the entire process for controlling fluoride concentration in the water was rigorous and complied with Brazilian guidelines, but according to testing, 96\% of samples were inadequate in terms of risks/benefits of fluoride use from water. The information obtained from the plant supervisor and the test data were thus mutually inconsistent. Based on these data, an independent water fluoride concentration control program is needed to ensure the benefits of dental caries prevention for the population.
\end{abstract}

Key words Fluoridation; Water Supply; Water Treatment; Water Analysis

Resumo O objetivo deste estudo foi avaliar o controle operacional da fluoretação da água na estação de tratamento (ETA) que abastece o Município de Niterói, Rio de Janeiro, durante o período de janeiro a dezembro de 2000. Um questionário elaborado para avaliar o processo de fluoretação da água foi respondido pelos responsáveis pelo tratamento da água na ETA. Além disso, amostras de água, antes e após a adição de flúor, foram coletadas quinzenalmente na ETA para a análise do flúor. As amostras foram analisadas por laboratório externo por meio de eletrodo íon específico. Embora os responsáveis pela ETA tenham afirmado que o processo de controle da fluoretação da água era rigoroso e seguia a legislação brasileira, observou-se que 96\% das amostras analisadas encontravam-se inadequadas, considerando-se os riscos/benefícios da fluoretação da água. Assim, verificou-se incoerência entre as informações obtidas pelos responsáveis pela fluoretação na ETA e os valores obtidos nas análises das amostras de água. Esses dados demonstram que deve ser estabelecido um programa independente de controle da concentração de flúor na água do município de Niterói, a fim de garantir à população os benefícios do flúor no controle e na prevenção da cárie dental.

Palavras-chave Fluoração; Abastecimento de Água; Tratamento da Água; Análise da Água 


\section{Introdução}

Ao longo dos anos, a odontologia tem passado por grandes mudanças relacionadas ao entendimento do processo saúde-doença, assumindo novas posturas preventivas em relação à cárie dental. Nas últimas décadas do século 20, a medida de maior impacto referente no controle do desenvolvimento dessa doença foi o uso de flúor (Cury, 2001).

Em relação à utilização do flúor em saúde pública, de acordo com dados da Organização Mundial da Saúde, a fluoretação das águas de abastecimento público tem sido uma das principais medidas envolvidas na redução dos índices de cárie em todo o mundo (WHO, 1994). Além disso, foi considerada nos Estados Unidos como uma das dez principais medidas de saúde pública do século 20 (Anonymous, 2001).

Entretanto, ainda que sejam conhecidos os benefícios da adição do flúor às águas como medida de promoção de saúde e prevenção da cárie dental, muitas são as cidades brasileiras que não dispõem desse processo ou não possuem uma política de vigilância sanitária que controle de forma satisfatória a sua execução (Calvo, 1996). Visto que o principal objetivo da utilização de flúor é maximizar seus benefícios, minimizando seus riscos, a existência de mecanismos que viabilizem sua adequada concentração na água torna-se indispensável para que a medida exerça o maior impacto possível na prevenção e controle da cárie, sem aumentar a prevalência de fluorose dental (Clarkson et al., 2000).

Nesta linha de raciocínio, a criação de mecanismos que controlem a concentração de flúor é fundamental para a melhoria da qualidade da água a ser fornecida à população, sendo, portanto, indispensável a ação correta da empresa responsável pelo seu tratamento e fluoretação (Cury, 1992; Narvai, 2001).

No que diz respeito ao Município de Niterói, Rio de Janeiro, pouco se sabe sobre o processo de fluoretação feito na estação de tratamento (ETA), bem como sobre a concentração de flúor presente na água tratada nessa estação. Partindo dessa premissa, o presente estudo desenvolveu-se no sentido de analisar o mecanismo de controle operacional da fluoretação da água executado na ETA que abastece o Município de Niterói, durante o período de janeiro a dezembro de 2000.

\section{Metodologia}

\section{Caracterização do estudo}

Segundo seus objetivos, o presente estudo pode ser classificado como uma pesquisa do tipo descritiva, uma vez que pretendeu descrever um fato (fluoretação da água de abastecimento) por meio de observação sistemática das suas características, sem intervenção nas variáveis (Lakatos \& Marconi, 1991).

Para tanto, contou-se inicialmente com a obtenção de dados qualitativos a respeito do sistema de fluoretação empregado na ETA de Imunana/Laranjal, mediante o preenchimento de um questionário pelos responsáveis pelo controle operacional da fluoretação da água. Os dados quantitativos foram obtidos por meio de pesquisa de campo e laboratorial (Lakatos \& Marconi, 1991; Santos, 1999), abrangendo as áreas de saúde coletiva e, mais especificamente, a área de políticas e estratégias públicas em saúde bucal. Por 12 meses consecutivos (janeiro a dezembro de 2000), foram analisadas amostras da água tratada e fluoretada na ETA que abastece Niterói, com vistas a avaliar o teor de flúor na água a ser distribuída à população.

$\mathrm{Na}$ fase de campo e laboratorial, foram coletadas quinzenalmente duas amostras da água bruta (proveniente dos rios Guapiaçu e Macacu, captada através do canal Imunana/Laranjal), a fim de se identificar a existência de flúor natural nos mananciais que abastecem a ETA. Também foram coletadas duas amostras quinzenais da água tratada, visando a detectar a concentração de flúor na água tratada disponibilizada aos munícipes.

\section{Coleta de informações relativas à fluoretação da água de abastecimento do Município de Niterói, Rio de Janeiro}

Com o objetivo de conhecer a realidade do $\mathrm{Mu}$ nicípio de Niterói, foi elaborado um questionário para ser respondido pela administração da ETA. Os seguintes itens foram abordados, de acordo com Schneider Filho et al. (1992): (1) situação da rede de abastecimento, tais como: número de fontes, estações de tratamento, áreas de abrangência e cobertura populacional; (2) média das temperaturas máximas anuais; (3) existência ou não de flúor natural nas águas de abastecimento; (4) teor de flúor a ser agregado às águas de abastecimento; (5) data de início da fluoretação, composto de flúor utilizado e possíveis períodos de interrupção do processo; (6) existência ou não de dados gerados pelo sistema de controle operacional da(s) empresa(s) 
de águas que servem à localidade; e (7) a existência e o conteúdo de regulamentação sobre a fluoretação da água no âmbito estadual e/ou municipal.

\section{Coleta da água}

Tomando-se por base a concentração de flúor, optou-se por fazer: (a) coleta da água do rio (bruta), realizada duas vezes por mês, durante os 12 meses do estudo, para que se pudesse identificar quaisquer alterações nos teores de flúor da água do rio que viessem a interferir em sua concentração final; (b) coleta da água tratada diretamente na estação de tratamento, também realizada duas vezes por mês, até o fim do estudo, a fim de se observarem quaisquer desvios nos teores de flúor, após fluoretação feita pela ETA.

As amostras coletadas foram remetidas ao Laboratório de Saúde Bucal do Programa de Pós-Graduação em Odontologia Social da Universidade Federal Fluminense (UFF), onde eram analisadas em duplicata, utilizando-se como valor referencial a média das duas leituras (avaliações). Contraprovas, tomadas ao acaso, foram realizadas no Laboratório de Bioquímica Oral da Faculdade de Odontologia de Piracicaba da Universidade Estadual de Campinas.

Para fins de avaliação, nenhuma das amostras extrapolou o período máximo de 150 dias de armazenamento, não havendo necessidade, portanto, de desprezar nenhuma amostra, segundo Prado et al. (1992).

\section{Análise laboratorial do íon flúor}

A metodologia seqüencial para medição do íon flúor na água foi realizada seguindo-se recomendações preconizadas por Schneider Filho et al. (1992), que se baseiam na dosagem direta dos íons flúor livres com o uso de um eletrodo íon seletivo para flúor, em conjunção com um medidor de atividade iônica. Para tal, utilizouse analisador de íons modelo HI-8417 (Hanna), eletrodo combinado seletivo para íon flúor (Orion 9609), béqueres, micropipetas, tubos de ensaio plásticos e estantes porta tubos de ensaio. Soluções de concentração conhecida de flúor foram preparadas a partir de uma solução-padrão de 100ppm de flúor.

Procedeu-se inicialmente à realização de curvas de baixa concentração; entretanto, a partir do momento em que se verificou a presença de $\mathrm{F}^{-}$na água, passou-se a confeccionar curvas de média concentração. Para as curvas de baixa, foram utilizadas soluções-padrão contendo de 0,0625ppm F a 1,00 ppm F e uma solução-teste de 0,40ppm F. Já para as curvas de média, utilizou-se de 0,20ppm F a 2,00ppm F e um teste de 1,00ppm F.

\section{Análise dos resultados}

Após a conversão dos valores de milivoltagem em concentração de flúor (ppm), foram confeccionadas planilhas, utilizando-se o programa Microsoft Excel 97, nas quais se fez a tabulação dos valores encontrados, levando-se em consideração: (a) amostras quinzenais de água do rio (bruta) no período do estudo; e (b) amostras quinzenais de água tratada na ETA durante o ano de 2000.

\section{Resultados}

A partir das informações obtidas nas respostas ao questionário (Tabela 1), verificou-se que não existe flúor nos mananciais que abastecem a ETA e que, desde o ano de 1996, esta procede à fluoretação das águas de abastecimento após o seu tratamento. Para tanto, segue-se a Portaria no 36 do Ministério da Saúde, considerando-se o valor ótimo residual de flúor, em média, de $0,7 \mathrm{mg} / \mathrm{l}$. Constatou-se também, pelas respostas ao questionário, que a taxa de aplicação média de flúor na água pela ETA é de 2,21 mg/l (Tabela 1), utilizando-se como composto o ácido fluossilícico $\left(\mathrm{H}_{2} \mathrm{SiF}_{6} \mathrm{PM}=144,1\right)$ aplicado diretamente na água filtrada, através de uma bomba dosadora de fluxo contínuo, sendo seu residual controlado por um operador, a cada hora, mediante análise laboratorial feita pela técnica espectofotométrica (Tabela 1).

É importante salientar que até o mês de novembro de 2000 o método utilizado pela ETA para a análise de flúor na água era o colorimétrico da alizarina, tendo sido substituído pelo espectofotométrico, por ser este mais apropriado.

Com relação às análises laboratoriais das amostras de água coletadas (Tabela 2) realizadas por laboratório independente, verificou-se que, em relação à água bruta, foi encontrada uma baixa concentração de flúor durante todo o período do estudo. Assim, um valor desprezível $(0,03 p p m$ F a $0,05 p p m$ F) foi observado em $100 \%$ das amostras, mantendo-se constante por todo o ano, fato que corroborou as informações obtidas na ETA.

A respeito da água tratada, foi observada (Tabela 2) uma grande variação da concentração de flúor (0,03ppm F a 1,49ppm F) durante todo o período do estudo, sendo que $96 \%$ das amostras possuíam concentração inadequada. 
Tabela 1

Aspectos relevantes obtidos mediante questionário realizado com os responsáveis pelo controle operacional da fluoretação da água dentro da estação de tratamento de Niterói, Rio de Janeiro.

\begin{tabular}{ll}
\hline Questionamentos & Respostas \\
\hline $\begin{array}{l}\text { Situação da rede de abastecimento } \\
\text { Existência de flúor nos mananciais }\end{array}$ & $\begin{array}{l}\text { O volume de água tratada pode chegar a 7,0m/s } \\
\text { Não existe flúor nos rios que abastecem a ETA } \\
\text { Início da fluoretação/composto/ método de aplicação } \\
\text { Outubro de 1996/ácido fluossilícico/aplicado com bomba } \\
\text { dosadora }\end{array}$ \\
$\begin{array}{ll}\text { Regulamentação seguida pela ETA } \\
\text { Residual de flúor na água }\end{array}$ & $\begin{array}{l}\text { Residual médio de 0,7mg F/L taxa de aplicação média } \\
\text { de 2,21mg/l de ácido fluossilícico }\end{array}$ \\
Dados gerados pelo controle operacional na ETA & $\begin{array}{l}\text { Controle residual diário/registro em boletins próprios } \\
\text { Técnica de espectrofotometria }\end{array}$ \\
Pontrole dos teores de flúor & $\begin{array}{l}\text { Apenas para manutenção do sistema ou por ser um } \\
\text { produto com produção sazonal }\end{array}$ \\
\hline
\end{tabular}

Tabela 2

Média quinzenal da concentração de flúor na água bruta (rio) e na água tratada (ETA de Imunana/Laranjal) no período de janeiro a dezembro de 2000.

\begin{tabular}{|c|c|c|c|c|c|c|}
\hline Quinzenas dos meses do ano & Rio 1 & Rio 2 & Média rio & ETA 1 & ETA 2 & Média ETA \\
\hline Janeiro (1 $\underline{a})$ & 0,03 & 0,02 & 0,03 & 0,04 & 0,04 & 0,04 \\
\hline Janeiro (2aa) & - & - & - & $0,04^{*}$ & $0,05^{\star}$ & 0,05 \\
\hline Fevereiro (1 $\underline{a})$ & - & - & - & $0,03^{*}$ & $0,03^{*}$ & 0,03 \\
\hline Fevereiro (2a $)$ & - & - & - & $0,04 *$ & $0,05^{\star}$ & 0,05 \\
\hline Março (1a) & - & - & - & $0,03 *$ & $0,03^{*}$ & 0,03 \\
\hline Março (2a) & - & - & - & $1,07^{*}$ & 1,21 * & 1,14 \\
\hline Abril (1 $\underline{a})$ & 0,04 & 0,04 & 0,04 & 0,93 & 0,96 & 0,95 \\
\hline Abril (2a $a)$ & 0,04 & 0,03 & 0,04 & 1,01 & 1,02 & 1,02 \\
\hline Maio (1a) & - & - & - & $1,07 *$ & $1,06^{*}$ & 1,07 \\
\hline Maio (2a & - & - & - & $0,05^{*}$ & $0,05^{*}$ & 0,05 \\
\hline Junho (1a) & - & - & - & $0,03^{*}$ & $0,03^{*}$ & 0,03 \\
\hline Junho (2a) & 0,03 & 0,04 & 0,04 & 0,04 & 0,04 & 0,04 \\
\hline Julho (1a) & 0,04 & 0,04 & 0,04 & 0,04 & 0,04 & 0,04 \\
\hline Julho (2ạ) & 0,05 & 0,04 & 0,05 & 1,20 & 1,22 & 1,21 \\
\hline Agosto (1a) & 0,03 & 0,04 & 0,04 & 0,12 & 0,11 & 0,12 \\
\hline Agosto (2a $)$ & 0,03 & 0,03 & 0,03 & 0,03 & 0,03 & 0,03 \\
\hline Setembro (1 $1 \underline{a})$ & 0,04 & 0,03 & 0,04 & 1,50 & 1,48 & 1,49 \\
\hline Setembro (2a) & 0,02 & 0,03 & 0,03 & 0,03 & 0,03 & 0,03 \\
\hline Outubro (1a) & 0,05 & 0,04 & 0,05 & 0,13 & 0,11 & 0,12 \\
\hline Outubro (2a) & 0,03 & 0,03 & 0,03 & 1,01 & 1,00 & 1,01 \\
\hline Novembro (1a) & 0,04 & 0,04 & 0,04 & 1,02 & 1,03 & 1,02 \\
\hline Novembro (2âa) & 0,03 & 0,04 & 0,04 & 0,46 & 0,48 & 0,47 \\
\hline Dezembro (1â) & 0,03 & 0,03 & 0,03 & 0,64 & 0,65 & 0,65 \\
\hline Dezembro (2a) & 0,04 & 0,03 & 0,04 & 0,09 & 0,08 & 0,09 \\
\hline Média anual & 0,04 & 0,03 & 0,04 & 0,44 & 0,45 & 0,45 \\
\hline
\end{tabular}

ETA = estação de tratamento; Rio 1 e Rio 2 = Primeira e segunda amostras de água do rio, respectivamente; Média rio = valor médio entre os valores de Rio 1 e Rio 2; ETA 1 e ETA 2 = Primeira e segunda amostras de água tratada na ETA, respectivamente; Média ETA = valor médio entre os valores de ETA 1 e ETA 2.

* Coletas feitas fora da ETA/Laranjal (em um estabelecimento comercial). 
Esses valores demonstram a grande incoerência existente entre as informações fornecidas pela ETA em resposta ao questionário e os dados obtidos pelo heterocontrole da fluoretação.

Destaque-se que, em algumas quinzenas do período de coleta (Tabela 2), uma proibição de caráter verbal, por parte da Companhia Estadual de Águas e Esgotos (Cedae), impossibilitou a coleta de água tratada dentro da ETA. A coleta, então, foi realizada no ponto mais próximo da estação (um estabelecimento comercial que se localizava a aproximadamente 50 metros da entrada da ETA). Nesses momentos de proibição, também foi impossível efetuar a coleta da água do rio (bruta), que era feita diretamente de uma bica receptora próxima aos tanques de tratamento dentro da estação ( Tabela 2).

\section{Discussão}

Atualmente, não resta dúvida de que o flúor tem um papel fundamental na promoção da saúde bucal, sendo considerado a pedra angular da prevenção da cárie dental, tanto em crianças como em adultos (Clarkson \& McLoghlin, 2000; Easley, 1995).

Para o Município de Niterói, considerandose os dados obtidos no Instituto de Geoquímica da UFF, a temperatura média anual de 2000 foi de 28,4oC. Tomando-se os valores sugeridos por Schneider Filho et al. (1992), pôde-se determinar que a concentração ótima de flúor na água da cidade deveria ser em média de 0,7 ppm F (0,6 ppm F a 0,8 ppm F) para que se pudesse obter o máximo de efeito preventivo, sem preocupações com os riscos de fluorose dental.

Em algumas cidades brasileiras que possuem água fluoretada, os percentuais médios de redução de cárie encontrados variaram de $29 \%$ a $79 \%$. Enquanto os valores menos expressivos de decréscimo foram encontrados por Rocchi et al. (1991) em Bauru, São Paulo (29\% a $36 \%$ ), os índices de diminuição da incidência da doença se mostraram mais elevados na cidade de Goiânia, Goiás (57,1\%), em estudo de Freire et al. (1997). Já na cidade de Piracicaba, São Paulo, segundo Basting et al. (1997), o percentual médio de redução de cárie observado após 25 anos de fluoretação da água foi de $79 \%$.

Em relação ao município alvo do presente estudo, considerando-se os dados obtidos no Primeiro Inquérito Epidemiológico de Prevalência de Cárie Dental e Necessidade de Tratamento em Escolares no Município de Niterói (Coordenação de Saúde Bucal, 2000), pode-se destacar que, embora o CPO-D médio encontrado
$(2,81)$ situe-se dentro dos níveis de prevalência considerados moderados, ainda existe disparidade nos valores identificados, principalmente quando se considera o nível sócio-econômico das crianças estudadas. Esse fato denota a necessidade de manutenção de medidas de prevenção e controle da cárie dental, com grande abrangência e acessibilidade a todas as camadas da população, o que poderia ser obtido com uma efetiva fluoretação das águas de abastecimento.

Embora no Brasil diversos estudos tenham demonstrado a eficácia da fluoretação das águas de abastecimento público ao longo dos anos, bem como o seu impacto na prevenção e redução dos índices de cárie da população, quando utilizada de maneira contínua, adequada e sob o controle de um sistema operacional e de vigilância efetivos (Basting et al., 1997; Freire et al., 1997; Rocchi et al., 1991), outros tendem a falhar no que diz respeito à adequação e regularidade dos níveis de flúor na água de consumo humano (Calvo, 1996; Correia et al., 2001; Freitas et al., 1996; Modesto et al., 1999).

Diante desse quadro e levando-se em consideração os resultados obtidos no presente estudo, podem-se identificar grandes distorções no sistema de controle operacional executado na ETA que abastece o município. E, ainda que a ETA tenha afirmado existir um controle operacional dos teores de flúor na água tratada em seus reservatórios centrais, as análises laboratoriais das amostras obtidas quinzenalmente na ETA de Imunana/Laranjal não demonstraram regularidade nas concentrações de flúor (Tabela 2).

A média anual dos teores de flúor igual a 0,45ppm e as oscilações (0,03ppm F a 1,49ppm F) nos valores encontrados, caracterizando um percentual de $96 \%$ de amostras com valores inadequados, certamente implicaram prejuízo dos benefícios advindos da fluoretação das águas de abastecimento público no Município de Niterói.

Outro fato que merece destaque diz respeito ao tipo de composto fluoretado utilizado e à quantidade e à forma pela qual este é acrescentado à água de abastecimento. Sabe-se que um dos compostos mais utilizados em todo o mundo na fluoretação das águas de abastecimento público é o ácido fluossilícico (Brasil, 1975; Murray, 1992; Reeves, 1996; Schneider Filho et al., 1992). Sua aplicação deve ser feita diretamente no suprimento de água por meio de uma bomba dosadora, sendo necessário também um dispositivo automático de monitoramento da injeção de ácido, ligado a um alarme capaz de disparar toda vez que houver irregularidade 
na aplicação do composto fluoretado (Reeves, 1996).

Na ETA de Imunana/Laranjal, embora se utilize o ácido fluossilícico aplicado por meio de uma bomba dosadora de fluxo contínuo, não existe mecanismo automático de controle nas oscilações da injeção do ácido. Assim como se faz em relação ao cloro, a cada hora é efetuada uma análise da concentração de flúor na água e, em caso de necessidade, as correções da injeção de flúor, bem como o seu controle, são feitas por um operador. Tal fato pode ter contribuído para a grande variabilidade da concentração de flúor encontrada em todo o período do estudo.

Embora os responsáveis pelo controle operacional da fluoretação tivessem ciência das incorreções do sistema, é importante destacar os esforços empreendidos pela ETA, baseados nos resultados da presente pesquisa, para ajustar os teores de flúor na água tratada, o que pôde ser verificado quando da mudança do método de análise inicialmente utilizado (visual de alizarina) para o espectrofotométrico (Spands).

Em relação a este último método, Murray (1992) aponta que o controle do conteúdo de flúor na água pode ser praticado com eletrodo de ionização específico e destaca que é fundamental que os operadores da ETA tenham recebido treinamento para a execução dessa tarefa. Tal preocupação é compartilhada pela Organização Mundial de Saúde, que preconiza a existência de equipamentos de alto padrão para o controle operacional, bem como a disponibilização dos compostos fluoretados e o treinamento de recursos humanos para administrar o sistema (WHO, 1994).

Além disso, ao se compararem os métodos colorimétricos com o eletrométrico, tomandose por base as mesmas amostras (Brossak et al., 1987), os primeiros tendem a superestimar a concentração de flúor presente na água. Esse fato pode ter influenciado diretamente os resultados do presente estudo, uma vez que a mesma água coletada e medida na ETA (alizarina e/ou Spands) e no Laboratório de Saúde Bucal do Programa de Pós-Graduação em Odontologia Social da UFF (eletrométrico) apresentava diferenças na concentração de flúor. Um exemplo disso ocorreu (por ocasião da troca do método de alizarina por Spands, no mês de novembro) quando as medições na ETA acusaram um teor de 0,60ppm, enquanto no Laboratório de Saúde Bucal observou-se um teor de 0,47ppm.

\section{Conclusões}

A ETA que abastece o Município de Niterói, Rio de Janeiro, procede de forma irregular à fluoretação da água, o que foi caracterizado pela variabilidade e descontinuidade nas concentrações de flúor encontradas nas amostras coletadas quinzenalmente.

O controle operacional da fluoretação da água não se mostrou suficientemente adequado no que diz respeito à manutenção de níveis ótimos de flúor na água de abastecimento público, no período de janeiro a dezembro de 2000.

Embora os esforços da ETA (Cedae) tenham sido evidentes, infelizmente apenas a mudança no método de análise dos teores de flúor na água, na prática, não se mostrou suficiente para promover uma constância nos valores encontrados, tampouco para mantê-los dentro de um nível considerado ótimo. Em nenhum momento a Cedae admitiu a possibilidade de erros provenientes do método de injeção de flúor na água, nem se mostrou receptiva à idéia de que alguns valores encontrados situavamse acima do ótimo recomendado.

\section{Agradecimentos}

A Waldomiro Vieira Filho, técnico do Laboratório de Bioquímica Oral da Faculdade de Odontologia de Piracicaba da Universidade Estadual de Campinas, e a Michelle Cecille Bandeira Teixeira, mestranda em Odontologia Social da Universidade Federal Fluminense (UFF), pelo auxílio na fase laboratorial da pesquisa. Este trabalho é parte da tese de doutoramento da primeira autora, apresentada como um dos requisitos do Programa de Pós-Graduação em Odontologia Social da UFF. À Coordenação de Aperfeiçoamento de Pessoal de Nível Superior pelo suporte financeiro ao presente estudo. 


\section{Referências}

ANONYMOUS, 2001. Recommendations for using fluoride to prevent and control dental caries in the United States. Centers for Disease Control and Prevention. MMWR, 50:1-42.

BASTING, R. T.; PEREIRA, A. C. \& MENEGHIM, M. C., 1997. Avaliação da prevalência da cárie dentária em escolares do município de Piracicaba-SP, Brasil, após 25 anos de fluoretação das águas de abastecimento público. Revista de Odontologia da Universidade de São Paulo, 11:287-292.

BRASIL, 1975. Decreto no 76.872, de 22 de dezembro de 1975, Regulamenta a Lei no 6.050 de 24 de maio de 1974. Dispõe sobre a fluoretação de sistemas públicos de abastecimento. Brasília: Diário Oficial da União, Seção 1, p. 16997.

BROSSAK, G. E.; McTIGUE, D. J. \& KUTHY, R. A., 1987. The use of a colorimeter in analysing the fluoride content of public well water. Pediatric Dentistry, 9:204-207.

CALVO, M. C. M., 1996. Situação da Fluoretação de Águas de Abastecimento Público no Estado de São Paulo - Brasil. São Paulo. Dissertação de Mestrado, São Paulo: Departamento de Prática de Saúde Pública, Universidade de São Paulo.

CLARKSON, J. J.; BARMES, D.; HARDWICK, K. \& RICHARDSON, L. M., 2000. International Collaborative Research on Fluoride. Journal for Dental Research, 79:893-904.

CLARKSON, J. J. \& McLOUGHLIN, J., 2000. Role of fluoride in oral health promotion. International Dental Journal, 50:119-126.

COORDENAÇÃO DE SAÚDE BUCAL, 2000. Primeiro Inquérito Epidemiológico de Prevalência de Cárie Dentária e Necessidade de Tratamento em Escolares de 6 e 12 anos no Município de Niterói/Rio de Janeiro: Relatório Final 1a Parte. Niterói: Coordenação de Saúde Bucal, Vice-Presidência de Atenção Ambulatorial Coletiva e da Família, Fundação Municipal de Saúde, Secretaria Municipal de Saúde. (mimeo.)

CORREIA, R. P.; FERREIRA Jr., C. D. \& MAIA, L. C., 2001. Análise da fluoretação da água de abastecimento público na zona sul do município do Rio de Janeiro. Pesquisa Brasileira em Odontopediatria e Clínica Integrada, 1:17-22.

CURY, J. A., 1992. Fluoretação da água: Benefícios, riscos e sugestões. Revista de Odontologia do Brasil Central, 2:32-33.

CURY, J. A., 2001. Uso do flúor e controle da cárie como doença. In: Odontologia Restauradora (L. N. Baratieri, M. A. C. Andrada \& S. Monteiro Jr., org.), pp. 33-68, São Paulo: Editora Santos.
EASLEY, M. W., 1995. Celebrating 50 years of fluoridation: A public health success history. British Dental Journal, 21:72-75.

FREIRE, M. C. M.; PEREIRA, M. F.; BATISTA, M. R. S.; BARBOSA, M. I. \& ROSA, A. G. F., 1997. Prevalência de cárie e necessidade de tratamento entre escolares de 6 a 12 anos de idade, Goiânia, GO, Brasil. Revista de Saúde Pública, 31:44-52.

FREITAS, V. P. S.; BRÍGIDO, B. M.; ALGE, M. E.; SILVA, C. L.; ZENEBON, O. \& ANTUNES, J. L. F., 1996. Fluoreto em água: Estudo de metodologia analítica e níveis encontrados na região de Campinas. Revista do Instituto Adolfo Lutz, 56:29-36.

LAKATOS, E. M. \& MARCONI, M. A., 1991. Metodologia Científica. 3a Ed. São Paulo: Editora Atlas.

MODESTO, A.; TANAKA, F. H. R.; FREITAS, A. D. \& CURY, J. A., 1999. Avaliação da concentração de fluoreto na água de abastecimento público do município do Rio de Janeiro. Revista Brasileira de Odontologia, 56:217-221.

MURRAY, J. J., 1992. Uso Correto de Fluoretos em Saúde Pública. São Paulo: Editora Santos.

NARVAI, P. C., 2001. Vigilância Sanitária da Fluoretação das Águas de Abastecimento Público no Município de São Paulo, Brasil, no Período 1990-1999. Tese de Livre Docência. São Paulo: Faculdade de Saúde Pública, Universidade de São Paulo.

PRADO, I. A. T.; BREVILLIERI, C. M.; NARVAI, P. C.; SCHNEIDER, D. A. \& MANFREDINI, M. A., 1992. Estabilidade do flúor em amostras de água. $R e$ vista Gaúcha de Odontologia, 40:197-199.

REEVES, T. G., 1996. Technical aspects of water fluoridation in the United States and overview of fluoridation engineering world-wide. Community of Dental Health, 13:21-26.

ROCCHI, V. A. P.; BOESSO, M. C. A.; BERNARDES, V. L. \& BASTOS, J. R. M., 1991. Fluoretação e saúde gengival. Revista Gaúcha de Odontologia, 39:228230.

SANTOS, A. R., 1999. Metodologia Científica: A Construção do Conhecimento. 1a Ed. Rio de Janeiro: De Paulo Editora.

SCHNEIDER FILHO, D. A.; PRADO, I. T.; NARVAI, P. C. \& BARBOSA, S. E., 1992. Fluoretação da água. Como fazer a vigilância sanitária? Cadernos de Saúde Bucal, 1:1-23.

WHO (World Health Organization), 1994. Fluorides and Oral Health. Who Technical Report Series. Geneva: WHO.

Recebido em 19 de abril de 2001

Versão final reapresentada em 10 de dezembro de 2001 Aprovado em 1 de julho de 2002 